\title{
Case Report \\ The Effect of Gallium Nitrate on Arresting Blood Flow from a Wound
}

\author{
Paul H. Goodley ${ }^{1}$ and Moshe Rogosnitzky ${ }^{2}$ \\ ${ }^{1}$ Department of Orthopaedics, Goodley Pain Clinic, Telz Stone 90840, Israel \\ ${ }^{2}$ Department of Medical Informatics, MedInsight Research Institute, \\ Telz Stone 90840, Israel
}

Correspondence should be addressed to Moshe Rogosnitzky, moshe@medinsight.org

Received 13 December 2010; Accepted 29 March 2011

Academic Editor: Elijah Dixon

Copyright (C) 2011 P. H. Goodley and M. Rogosnitzky. This is an open access article distributed under the Creative Commons Attribution License, which permits unrestricted use, distribution, and reproduction in any medium, provided the original work is properly cited.

A novel application of gallium nitrate, hitherto unreported, in reducing bleeding time from an open wound is presented. Experiments performed using simple punctures in the forearm demonstrated a very substantial reduction in bleeding time when a solution of gallium nitrate was applied relative to a control. This outcome was shown to be unaffected by the anticoagulant properties of warfarin. The mechanism for such action of gallium nitrate is unknown and merits further investigation, as do the possibilities for such an application to improve both civilian and defense trauma treatment modalities.

\section{Introduction}

Gallium nitrate, the gallium salt of nitric acid, is a drug predominantly used to treat symptomatic hypercalcemia secondary to cancer [1]. The postulated mechanism of action is that it prevents the breakdown of bone through the inhibition of osteoclast activity, thus lowering the amount of free calcium in the blood [2]. It has been shown to be more effective than several other antihypercalcemic drugs $[3,4]$. Gallium nitrate has also been used in the treatment of non-Hodgkin's lymphoma [5, 6], multiple myeloma [7], and Paget's disease of bone [8]. To the best of our knowledge, no effect of gallium on coagulation parameters has ever been reported to date.

Here we present a novel action of gallium nitrate, that of stemming blood flow from an open wound via a mechanism of action as yet undetermined. After the serendipitous discovery of the blood-flow arresting properties of gallium nitrate by one of our authors, the authors conducted an experiment on themselves to explore this discovery further and so determine the benefit of gallium in stopping the bleeding from wounds.

\section{Case Presentation}

This study was conducted on two subjects: one (Subject 1, S1) under the influence of warfarin and one not under the influence of warfarin (Subject 2, S2). Subject 1 was on longterm warfarin treatment at the time of the experiment; this was not expected to have a significant effect on primary hemostasis.

In both cases, a puncture of the medial mid-forearm with a number 11 scalpel blade to a depth of $4 \mathrm{~mm}$ was made (P1), producing prompt flow of blood as a steady slow stream down the forearm. This was gently wiped with gauze every 30 seconds without applying pressure. The time for bleeding to stop was noted.

A second puncture (P2) was then made following the same method as for the first puncture. At 5 seconds after 
TABLE 1: The effect of gallium nitrate in reducing bleeding times from simple punctures (P1 and P2) in both warfarin- and nonwarfarintreated subjects (S1 and S2), with observations.

\begin{tabular}{lcccc}
\hline \multirow{2}{*}{ Subject } & \multicolumn{2}{c}{ Time for bleeding to stop (s) } & \multirow{2}{*}{ Reduction in bleeding time (\%) } & Observations of P2 \\
& P1 (control) & P2 (gallium nitrate) & & Small pool of blood stayed about the incision site. \\
\hline S1 (warfarin) & 122 & 35 & $71 \%$ & Visible clot started to form once flow had ceased. \\
S2 (nonwarfarin) & 238 & 45 & $81 \%$ & .
\end{tabular}

puncture, once blood flow had commenced, aqueous gallium nitrate (14\%) solution (Eby Pharma LLC, Dripping Springs, TX 78620) was applied using a soaked cotton ball. The time for bleeding to stop was again noted.

\section{Results}

The times after which blood flow ceased for each subject and each puncture are noted in Table 1, along with pertinent observations of the presence or absence of clotting.

\section{Discussion}

In this experiment, gallium nitrate substantially reduced bleeding time from an open wound in both a warfarintreated subject (S1) and nonwarfarin-treated subject (S2) when compared to the control (a reduction in bleeding time from $122 \mathrm{~s}$ to $35 \mathrm{~s}$ for S1 versus $238 \mathrm{~s}$ to $45 \mathrm{~s}$ for $\mathrm{S} 2$ ). In this experiment, warfarin did not negate or interfere with the blood-stemming property of gallium nitrate. Interestingly, whilst gallium nitrate stemmed the flow of blood in both subjects, the warfarin-treated subject did not form a visible clot, whilst the nonwarfarin-treated subject formed a very visible brown clot.

The effect of gallium nitrate described herein requires further investigation and verification as part of a larger, randomized control study, particularly with regards to its mechanism of action (in particular, future experiments should use a standardized bleeding time method such as the Ivy Method or the Simplate II).

Gallium nitrate has known toxicities when used at higher dosages intravenously, especially over the longer term. Infusion at a rate of around $300 \mathrm{mg} / \mathrm{m}^{3} / \mathrm{d}$ causes renal toxicity and/or diarrhoea in around $15 \%$ of patients studied [2]. Microcytic anemia is a possibility, but no suppression of platelets or WBCs is seen; visual or auditory toxicities occur very rarely. However, this present application of gallium nitrate is a single, topical treatment with limited absorption. While questions of toxicity should be addressed in further trials, side effects comparable with intravenous use of gallium nitrate are not expected.

The discovery described in this paper would be of particular relevance to the fields of emergency and defense trauma treatment. One of the current most effective treatments for wounds in these situations is the application of a kaolin-treated gauze (e.g., in the commercial product QuikClot Combat Gauze $[9,10])$, which is known to induce coagulation $[11,12]$ by activation of Factor XII [13]. It may be that gallium nitrate interacts with coagulation factors in a manner similar to current commercial products; it would be important to examine whether this effect takes place only on open wounds or whether gallium nitrate also has an internal procoagulant effect, which would necessitate consideration when it is used as a therapeutic medicine.

This behavior of gallium nitrate would be a valuable addition to such kaolin-based products, as while their usage leads to high survival rates, they do not necessarily stop blood flow rapidly [10]. The possibilities for the use of gallium nitrate in such situations merit further exploration.

\section{Conclusions}

This paper has demonstrated the hitherto unknown ability of gallium nitrate to reduce bleeding time from an open wound. The experiments performed in this case study indicate that gallium nitrate can substantially reduce the blood flow time for simple punctures relative to a control. The mechanism by which this occurs is unknown, although this effect was not interfered with by the anticoagulant properties of warfarin.

This effect should be further explored, both to determine its mechanism of action and to exploit this property for improved management of trauma in both civilian emergency and defense medical situations.

\section{Conflict of Interests}

One of the authors (M. Rogosnitzky) has a pending patent application on the described use of gallium nitrate.

\section{Acknowledgment}

The authors acknowledge with gratitude the professional assistance of Daniel Holt.

\section{References}

[1] F. Cvitkovic, J. P. Armand, M. Tubiana-Hulin, J. F. Rossi, and R. P. Warrell Jr., "Randomized, double-blind, phase II trial of gallium nitrate compared with pamidronate for acute control of cancer-related hypercalcemia," Cancer Journal, vol. 12, no. 1, pp. 47-53, 2006.

[2] C. J. Chitambar, "Medical applications and toxicities of gallium compounds," International Journal of Environmental Research and Public Health, vol. 7, no. 5, pp. 2337-2361, 2010.

[3] R. P. Warrell Jr., R. Israel, M. Frisone, T. Snyder, J. J. Gaynor, and R. S. Bockman, "Gallium nitrate for acute treatment of cancer-related hypercalcemia: a randomized, double-blind comparison to calcitonin," Annals of Internal Medicine, vol. 108, no. 5, pp. 669-674, 1988.

[4] R. P. Warrell Jr., W. K. Murphy, P. Schulman, P. J. O’Dwyer, and G. Heller, "A randomized double-blind study of gallium 
nitrate compared with etidronate for acute control of cancerrelated hypercalcemia," Journal of Clinical Oncology, vol. 9, no. 8, pp. 1467-1475, 1991.

[5] J. K. Weick, R. L. Stephens, L. H. Baker, and S. E. Jones, "Gallium nitrate in malignant lymphoma: a Southwest Oncology Group study," Cancer Treatment Reports, vol. 67, no. 9, pp. 823-825, 1983.

[6] D. J. Straus, "Gallium nitrate in the treatment of lymphoma," Seminars in Oncology, vol. 30, no. 2, pp. 25-33, 2003.

[7] R. P. Warrell Jr., D. Lovett, F. A. Dilmanian, R. Schneider, and R. T. Heelan, "Low-dose gallium nitrate for prevention of osteolysis in myeloma: results of a pilot randomized study," Journal of Clinical Oncology, vol. 11, no. 12, pp. 2443-2450, 1993.

[8] R. S. Bookman, F. Wilhelm, E. Siris et al., "A multicenter trial of low dose gallium nitrate in patients with advanced Paget's disease of bone," Journal of Clinical Endocrinology and Metabolism, vol. 80, no. 2, pp. 595-602, 1995.

[9] M. Pahari, R. Moliver, D. Lo, and G. Basadonna, Presentation Poster, 2010, http://www.z-medica.com/ZMedica /media/photos/posters/2010-02.ASDIN-2010.pdf.

[10] A Combat Medical Systems ${ }^{T M}$ (Fayetteville NC, USA) product, 2010, http://www.combatmedicalsystems.com/Products /List/1/CategoryID/1/Level/1.aspx.

[11] J. Margolis, "Activation of plasma by contact with glass: evidence for a common reaction which releases plasma kinin and initiates coagulation," The Journal of Physiology, vol. 144, no. 1, pp. 1-22, 1958.

[12] J. Margolis, "The kaolin clotting time; a rapid one-stage method for diagnosis of coagulation defects," Journal of Clinical Pathology, vol. 11, no. 5, pp. 406-409, 1958.

[13] J. H. Griffin, "Role of surface in surface-dependent activation of Hageman factor (blood coagulation Factor XII)," Proceedings of the National Academy of Sciences of the United States of America, vol. 75, no. 4, pp. 1998-2002, 1978. 


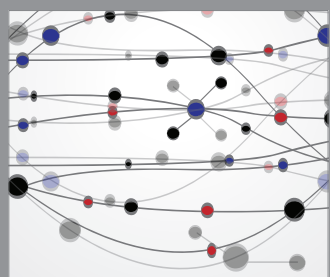

The Scientific World Journal
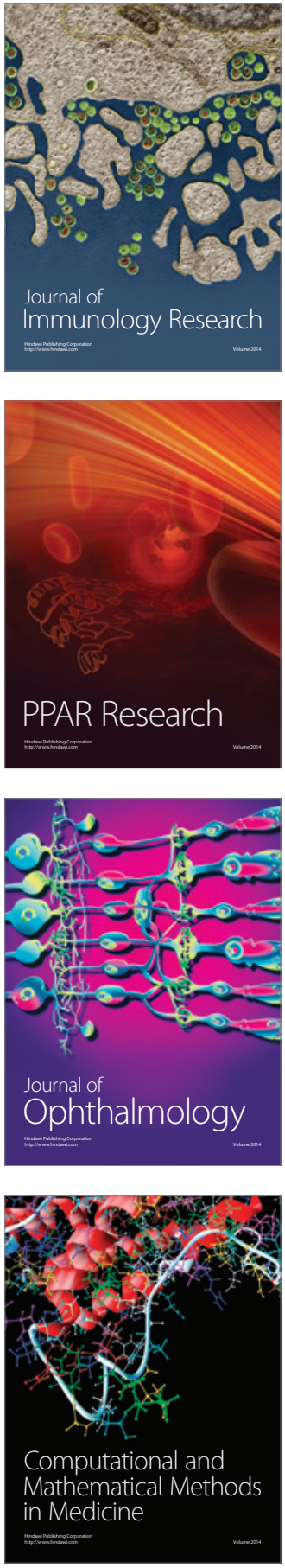

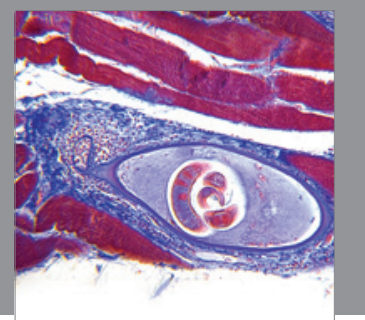

Gastroenterology

Research and Practice
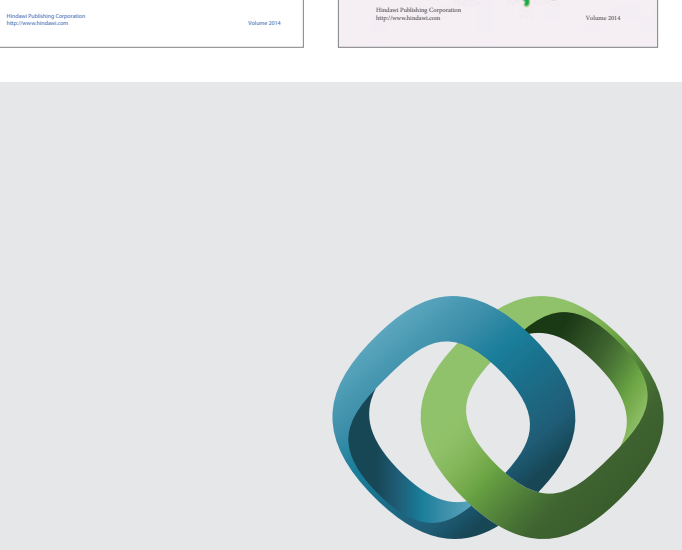

\section{Hindawi}

Submit your manuscripts at

http://www.hindawi.com
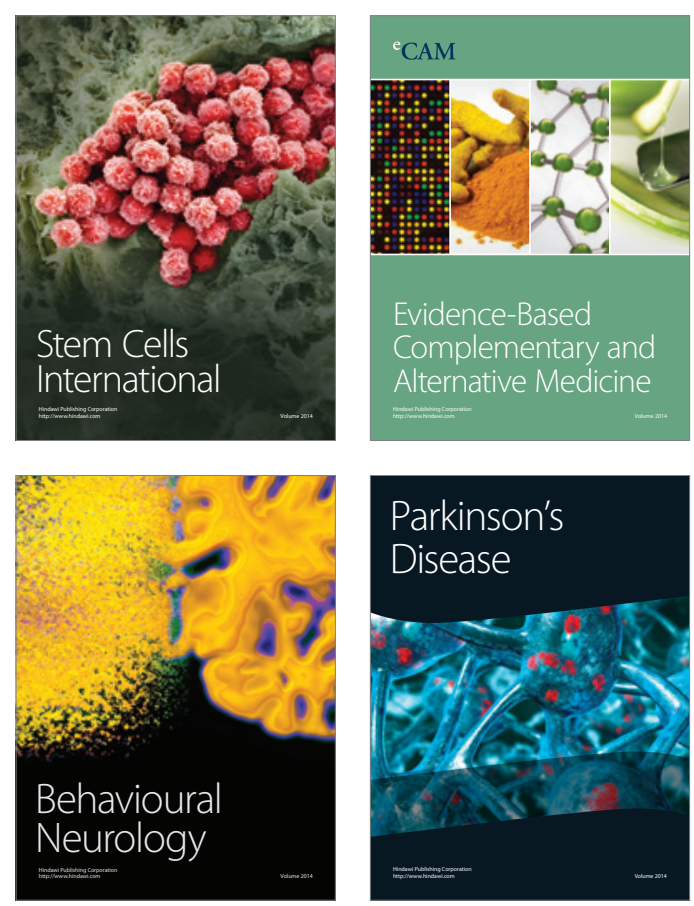

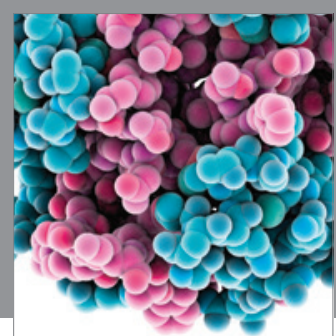

Journal of
Diabetes Research

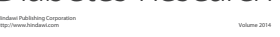

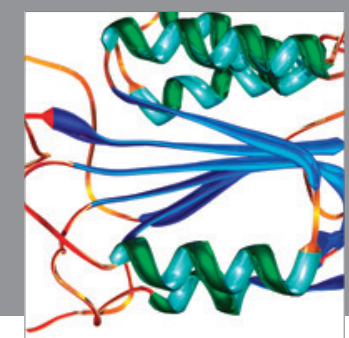

Disease Markers
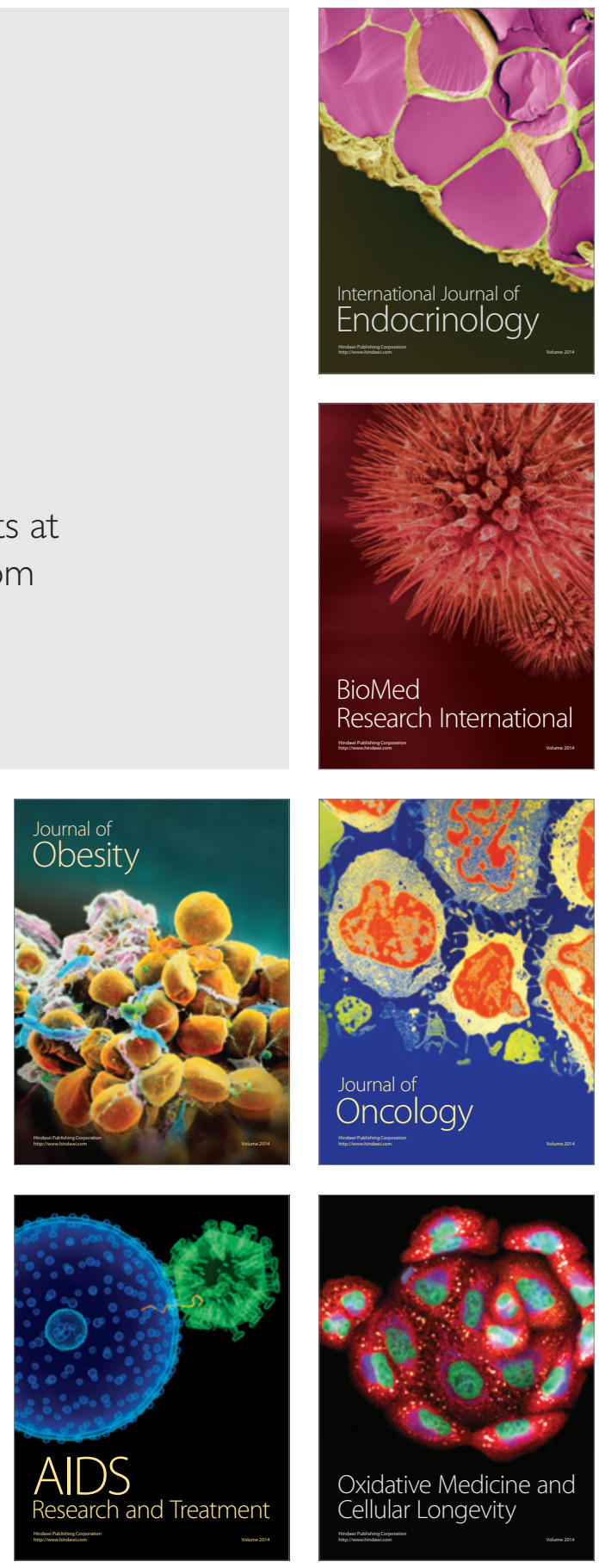